\title{
Distinct profiles of systemic biomarkers of oxidative stress in chronic human pathologies: Cardiovascular, psychiatric, neurodegenerative, rheumatic, infectious, neoplasmic and endocrinological diseases"
}

\author{
Michel Brack $^{1 \dagger}$, Olivier Brack ${ }^{2}$, Yves Ménézo ${ }^{3,4,5 \# \dagger}$, Dominique Bonnefont Rousselot ${ }^{6,7 \dagger}$, \\ Gerard Dreyfus $^{8,9 \dagger}$, M. John Chapman ${ }^{10,11,12 \dagger}$, Anatol Kontush ${ }^{10,11,12 \dagger}$ \\ ${ }^{1}$ Ge Sante et Retraite, Paris, France \\ ${ }^{2}$ Consultant en Statistiques, Esches, France \\ ${ }^{3}$ Procrelys, Maison Médicale Ambroise Paré, Lyon, France, \\ ${ }^{4}$ Laboratoire Clement, Paris, France \\ ${ }^{5}$ London Fertlity Associates, London, UK \\ ${ }^{6}$ Department of Metabolic Biochemistry, La Pitié Salpetriere-Charles Foix (AP-HP), Paris, France \\ ${ }^{7}$ Department of Biochemistry, Faculty of Pharmacy, Paris Descartes University, Paris, France \\ ${ }^{8}$ École Supérieure de Physique et de Chimie Industrielles, ESPCI, Paris, France \\ ${ }^{9}$ (CNRS UMR 7084), Laboratoire d'Électronique, Paris, France \\ ${ }^{10}$ Université Pierre et Marie Curie-Paris 6, Paris, France \\ ${ }^{11}$ UMR 939 "Dyslipoproteinemia, Inflammation and Atherosclerosis", INSERM, Paris, France \\ ${ }^{12}$ AP-HP, Groupe hospitalier Pitié-Salpétrière, Paris, France \\ Email: Olivier.brack@wanadoo.fr, "yves.menezo@gmail.com, dominique.bonnefont-rousselot@parisdescartes.fr, \\ Gerard.dreyfus@scpi.fr, john.chapman@upmc.fr, anatol.kontush@upmc.fr
}

Received 2 January 2013; revised 4 February 2013; accepted 21 February 2013

\begin{abstract}
Oxidative stress is involved in chronic and acute pathologies: cardiovascular, neurodegenerative, neoplastic, inflammatory and infectious diseases. Clinical trials focused on prevention of cardiovascular and neoplastic diseases involving antioxidant supplementation have however provided predominantly negative obserations in large-scale studies. Screening of patient cohorts to assess baseline oxidative stress on the basis of a biomarker profile is decisive but lacking. For the first time, we evaluated the level of oxidative stress, testing more than 10 established biomarkers, in a comprehensive initial survey of 617 patients displaying chronic human pathologies. Multiple diseasespecific abnormalities were identified in plasma, whole blood and/or urine. This is the case for vitamins and oligo elements, vitamin $C$, vitamin $E$, $\beta$-carotene, selenium, zinc and copper; endogenous antioxidants such as reduced and oxidised glutathione, thiols, urate, and glutathione peroxidase activity, and a biomarker of oxidative DNA damage (8-hydroxy-2'-deoxyguanosine). The distinct biomarker profiles suggest the involvment of multiple forms of oxidative insults which are
\end{abstract}

\footnotetext{
*The authors declare no conflict of interest.

${ }^{\#}$ Corresponding author.

${ }^{\dagger}$ Contributed equally to this work.
}

in some way partially specific to each pathological condition. This finding is in favor of the determination of an integrated score to combine contributions of distinct biomarkers, in order to screen patients presenting elevated levels of oxidative stress.

Keywords: Vitamin C; Vitamin $\mathrm{E} ; \beta$-Carotene; Glutathione; Thiols; Urate;

8-Hydroxy-2'-Deoxyguanosine

\section{INTRODUCTION}

It is well established that oxidative stress is involved in a spectrum of acute and chronic pathologies, including cardiovascular, neurodegenerative, inflammatory, neoplasmic and infectious diseases [1-4]. Moreover, oxidative stress plays a key role in aging [5]. Adverse effects of oxidative stress on human health are induced by free radical damages to a wide spectrum of biomolecules: this includes proteins, lipids and nucleic acids. The insults lead to oxidative modifications with concomitant functional defects. Biomolecules are protected from oxidative decays through the action of multiple antioxidative systems: those of exogenous origin, primarily provided through dietary intake, and those of endogenous origine, originating from the red ox regulation metabolism [1]. 
Levels of oxidative stress can be assessed by biomarkers. Three major groups can be defined: exogenous antioxidants (e.g. vitamin C, vitamin E, carotenoids), endogenous antioxidants (e.g. glutathione, thiols, uric acid), and biomarkers of oxidative damage (protein, lipid and nucleic acid oxidation products) [6-8]. Multiple forms of oxidative insults may exist in vivo, depending upon functional relationships between major oxidative species such as one- or two-electron reactive oxygen, nitrogen and chlorine derivatives. Distinct profiles of oxidative modification, and in turn, of oxidative stress biomarkers are then observed. Systemic biomarkers of oxidative stress can be observed in blood, plasma and/or urine as the results of an imbalance between pro and anti-oxidants. The diversity of oxidative species implies that the choice of biomarkers, which can be universally applied to characterise systemic oxidative stress in living organisms, constitutes a major challenge. Indeed, pioneering comprehensive comparative studies addressing this issue have recently been initiated in an animal model of oxidative stress by the US National Institute of Environmental Health Sciences $[9,10]$.

So far, analyses of oxidative stress biomarkers have primarily focused on specific diseases, notably of cardiovascular, neurodegenerative and inflammatory origin. Screening of subjects at high risk to assess oxidative stress on the basis of a profile of biomarkers appears however to be of relevance: especially as recent largescale studies of the potential relationships between antioxidant supplementations and incidence of cardiovascular disease and cancer have been poorly significant. Indeed, the lack of efficiency of dietary supplementation with vitamin $\mathrm{E}$, vitamin $\mathrm{C}$ or other antioxidants to reduce risk of cardiovascular disease and cancer has repeatedly been proposed without knowing the baseline values [11-13]. The absence of such data have resulted in antioxidant supplementations in subjects whose levels of oxidative stress were within the normal range. In order to compare systemic biomarker profiles of oxidative stress across a range of chronic human pathologies, several established biomarkers of oxidative stress, were evaluated in plasma, whole blood and/or urine. Endogenous antioxidants i.e. reduced and oxidised glutathione, thiols, urate, activity of glutathione peroxidase (GPx) and a biomarker of oxidative damage (8-hydroxy-2'-deoxyguanosine $(8-\mathrm{OHdG})$ have been measured. Common exogenously-supplied substances (vitamin $\mathrm{C}$, vitamin $\mathrm{E}, \beta$ carotene, selenium, zinc, copper) have been also assessed. Distinct profiles of biomarkers of oxidative stress were identified in these diseases, suggesting the involvement of multiple forms of oxidative insults roughly specific to each pathologies.

\section{MATERIAL AND METHODS}

Patients: Subjects were recruited at the Clinical Center for Oxidative Stress (Paris, France) over the period from 2002 to 2005 . The type of study does not request an approval of any ethical comittee but the patients had to sign a informed consent form. Profiles of biomarkers of oxidative stress were determined in plasmas from 617 subjects (195 males, 422 females) who decided to visit the hospital center to establish their profiles. Clinical and biological parameters were equally measured in each subject. The majority of subjects displayed clinicallyconfirmed diagnoses as follows: cardiovascular disease $(\mathrm{n}=136)$, psychiatric disease (depressive syndrome or anxiety; $n=98$ ), neurodegenerative disease (Alzheimer's disease, Parkinson's disease or multiple sclerosis; $n=61$ ) rheumatic disease $(\mathrm{n}=34)$, infectious disease (HIV or hepatitis $C(n=28)$, neoplasmic disease (cancer; $n=24)$ and endocrinological disease (thyroid dysfunction, $\mathrm{n}=$ 20). Each diagnosis was made in a specialised external clinical department using an internationally accepted definition for a given disease. In 75 subjects, the simultaneous presence of multiple (two or more) pathologies was diagnosed; these subjects were considered as polypathic and excluded from statistical analyses. Subjects (n $=127$ ) who contacted our Center in the absence of any known symptoms and who were free of a clinical diagnosis were considered as healthy controls. The remaining subjects $(\mathrm{n}=14)$ displayed relatively rare pathological conditions and were therefore excluded from statistical analyses.

A-Blood samples: Venous blood $(20 \mathrm{ml})$ was drawn from the cubital vein into Vacutainer tubes containing either EDTA or heparin as anticoagulants after an overnight fast. Plasmas were immediately separated by centrifugation at $3000 \mathrm{rpm}$ for 10 minutes and frozen at $-80^{\circ} \mathrm{C}$ until analysis. Urine was collected on the same visit and used for biomarker analyses within $24 \mathrm{~h}$.

B-Biomarkers of oxidative stress: The typical profile of biomarkers of oxidative stress included measurements of substances of exogenous origin (vitamin $\mathrm{C}$, vitamin $\mathrm{E}$, $\beta$-carotene, selenium, zinc, copper), endogenous antioxidants (reduced and oxidised glutathion, thiols, urate, GPx activity) and a biomarker of oxidative DNA damage (8-OHdG) in plasma, whole blood or urine.

B1-Vitamins: Determination of vitamin C: Vitamin $\mathrm{C}$ (ascorbate) was spectrophotometrically measured in plasma stabilized with $10 \%$ metaphosphoric acid as the reduction of 2,6-dichlorophenolindophenol using a Perkin Elmer Lambda 40 spectrophotometer [14]. Determination of vitamin $\mathrm{E}$ and $\beta$-carotene: Vitamin $\mathrm{E}$ (the sum of its major forms, $\alpha$ - and $\gamma$-tocopherols) and $\beta$-carotene were simultaneously determined by HPLC (Alliance Waters, USA) coupled with a diode array detector (PDA 2996, Waters, USA) [15]. Plasma levels of vitamin E were normalized to total plasma cholesterol which was measured by a standard colorimetric kit containing cho- 
lesterol oxidase.

B2-Determination of oligoelements: Plasma levels of selenium, zinc and copper were measured using inductively coupled plasma-mass spectroscopy [16].

B3-Endogenous antioxidants: Determination of reduced and oxidised glutathione: Reduced (GSH) and oxidized (GSSG) glutathione were measured in whole blood using a Bioxytech GSH/GSSG-412TM kit (OxisResearch, Portland, USA). Initially developed by Tietze [17], this method employs Ellman's reagent (5,5'-dithiobis-2-nitrobenzoic acid, DTNB) which reacts with GSH to form a product spectrophotometrically detectable at $412 \mathrm{~nm}$. The thiol-scavenging reagent, 1-methyl-2-vinylpyridinium trifluoromethanesulfonate, was used to prevent oxidation of GSH to GSSG during sample processing. GSSG was calculated as the difference between total glutathione (determined after reduction of GSSG to GSH by gutathione reductase and NADPH) and GSH. Determination of total thiols and uric acid: Total plasma sulfhydryl groups were determined spectrophotometrically at $412 \mathrm{~nm}$ after their reaction with DTNB [18]. Plasma urate was measured using a commercially available analytical test (Kodak Ektachem DT Slides, Eastman Kodak Company, Rochester, England).

B4-Enzymes involved in Glutathione metabolism: Determination of glutathione peroxidase activity: GPx activity was measured in erythrocytes using a comercially available kit (Randox Laboratories Ltd Antrim UK).

B5-Determination of DNA decays: Determination of 8-hydroxy-2'-deoxyguanosine: Competitive ELISA was used for the quantitative measurement of the oxidative DNA adduct 8-OHdG in fresh urine samples (Japan Institute for the Control of Aging, Japan). The concentration of 8-OHdG was normalised to creatinine urine levels and expressed as $\mathrm{ng} / \mathrm{mg}$ creatinine.

C-Statistical analysis: All the performed statistical tests take into account the sample size. For each dataset the normality of the distribution was assessed using a Shapiro and Wilk test (taking care of samples sizes). Data are shown as means \pm standard deviations for normally distributed variables and as medians (range) for the rest. Significance of between-group differences was calculated using analysis of variance; Fisher's F-test was used in case of homogeneous variance and AspinWelch's test in case of non-homogeneous variance. Pearson's moment-product correlation coefficients were calculated to evaluate relationships between variables. All calculations were performed using $\mathrm{Jmp}^{\circledR}$ SAS-Institute software, release 6.0.

\section{RESULTS}

Subjects with cardiovascular disease $(62.7 \pm 12.4$ years, $\mathrm{p}<0.001)$, neurodegenerative disease $(67.0 \pm 16.6$ years, $\mathrm{p}<0.001)$, rheumatic disease $(60.7 \pm 14.6$ years, $\mathrm{p}<$ $0.001)$ and cancer $(62.0 \pm 14.8$ years, $\mathrm{p}<0.01)$ are significantly older than in control group $(51.8 \pm 9.2$ years $)$; by contrast, subjects presenting psychiatric $(52.6 \pm 11.6$ years), infectious (50.8 \pm 11.6 years) and endocrinological (56.5 \pm 9.2 years) disease present no difference in age. Patients with rheumatic $(220 \pm 31 \mathrm{mg} / \mathrm{dl}, \mathrm{p}<0.05)$ and endocrinological $(219 \pm 24 \mathrm{mg} / \mathrm{dl}, \mathrm{p}<0.05)$ pathologies display significantly higher plasma level of total cholesterol vs controls $(204 \pm 39 \mathrm{mg} / \mathrm{dl})$, whereas infectious diseases induce hypocholesterolemia $(189 \pm 48, p<0.01$ vs controls).

Vitamins (Table 1): Plasma level of vitamin C (ascorbate), does not significantly differ between the different groups. It tends to decrease in the neurodegenerative disease group $(-10 \%, p=0.16)$. Absolute plasma concentration in vitamin $\mathrm{E}$ (expressed as $\mu \mathrm{mol} / \mathrm{l})$ are significantly reduced $(-15 \%, \mathrm{p}<0.05)$ in subjects with infectious disease (Table 1). Patients with cardiovascular disease display a significantly high concentrations of vitamin E vs control; this probably reflects the slightly increased level of total cholesterol in cardiovascular disease group $(+3 \%, p=0.19)$, as cholesterol-normalised levels of vitamin $\mathrm{E}$ are similar in the two groups (Table 1). By contrast, cholesterol-normalised level of vitamin $E$ is significantly lower in the psychiatric pathology $(-8 \%$, $p<0.001)$, infectious $(-12 \%, p<0.001)$ and endocrinological disease groups $(-6 \%, \mathrm{p}<0.05)$. It tends to decrease in rheumatic disease group $(-5 \%, \mathrm{p}=0.09$ vs controls; Table 1). Finally, the vitamin C/ vitamin $\mathrm{E}$ molar ratio does not differ between the groups; even if a trend towards a decrease can be observed in the cardiovascular disease group $(1.44 \pm 0.61)$ vs controls $(1.56 \pm$ $0.63, \mathrm{p}=0.18)$. Plasma concentrations of $\beta$-carotene differ significantly in the neurodegenerative disease group $(-28 \%, \mathrm{p}<0.05$, vs control).

Oligoelements (Table 2): Selenium concentration in plasma $(+21 \%, \mathrm{p}<0.01)$ and zinc $(+12 \%, \mathrm{p}<0.05)$ are significantly higher in subjects with rheumatic disease vs controls (Table 2). Plasma concentrations of copper are significantly lower $(-7 \%, \mathrm{p}<0.05)$ in subjects with neurodegenerative disorders. A trend towards a similar feature is observed for copper $(-7 \%, \mathrm{p}=0.06)$.

Endogenous antioxidants (Table 3): Plasma level of GSH tends to decrease in subjects with cancer $(-5 \%, \mathrm{p}=$ $0.06)$ and endocronological disease $(-4 \%, \mathrm{p}=0.13)$. Level of GSSG is lower in the neurodegenerative disorders group $(-34 \%, p<0.05$ vs controls). The GSH/ GSSG ratio is significantly depressed in patients with infectious $(-10 \%, \mathrm{p}<0.001)$ and rheumatic $(-31 \%, \mathrm{p}<$ $0.05)$ diseases; but significantly elevated in individuals with psychiatric $(+4 \%, \mathrm{p}<0.001)$, neurodegenerative $(+29 \%, \mathrm{p}<0.01)$ and endocrinological $(+21 \%, \mathrm{p}<0.001)$ 
Table 1. Plasma levels of exogenous antioxidants in diverse human pathologies.

\begin{tabular}{ccccccccc}
\hline & $\begin{array}{c}\text { Controls } \\
(\mathrm{n}=127)\end{array}$ & $\begin{array}{c}\text { Cardiovascular } \\
\text { disease } \\
(\mathrm{n}=136)\end{array}$ & $\begin{array}{c}\text { Psychiatric } \\
\text { disease } \\
(\mathrm{n}=98)\end{array}$ & $\begin{array}{c}\text { Neurodegenerative } \\
\text { disease } \\
(\mathrm{n}=61)\end{array}$ & $\begin{array}{c}\text { Rheumatic } \\
\text { disease } \\
(\mathrm{n}=34)\end{array}$ & $\begin{array}{c}\text { Infectious } \\
\text { disease } \\
(\mathrm{n}=28)\end{array}$ & $\begin{array}{c}\text { Cancer } \\
(\mathrm{n}=24)\end{array}$ & $\begin{array}{c}\text { Endocrinological } \\
\text { disease }(\mathrm{n}=20)\end{array}$ \\
\hline Vitamin $\mathrm{C}(\mu \mathrm{M})$ & $54.1 \pm 19.4$ & $52.1 \pm 20.1$ & $56.6 \pm 23.9$ & $48.6 \pm 26.4$ & $59.5 \pm 21.2$ & $51 \pm 29$ & $55.3 \pm 18.9$ & $57.4 \pm 16.6$ \\
$\begin{array}{c}\text { Vitamin } \mathrm{E}(\mu \mathrm{M}) \\
\quad 34.9 \pm 7.2\end{array}$ & $\mathbf{3 6 . 6} \pm \mathbf{9 . 5 ^ { * }}$ & $34.0 \pm 7.6$ & $35.1 \pm 7.7$ & $34.6 \pm 7.4$ & $\mathbf{2 9 . 5} \pm \mathbf{6 . 5}^{*}$ & $37.2 \pm 8.7$ & $38.3 \pm 7.7$ \\
$\begin{array}{c}\text { Vitamin } \mathrm{E} \\
(\mathrm{nmol} / \mathrm{mg} \\
\text { cholesterol })\end{array}$ & $17.5 \pm 3.9$ & $18.4 \pm 5.3$ & $\mathbf{1 5 . 8} \pm \mathbf{2 . 4 ^ { * }}$ & $17.0 \pm 3.5$ & $16.2 \pm 3.0$ & $\mathbf{1 5 . 1} \pm \mathbf{2 . 4}^{*}$ & $16.8 \pm 2.7$ & $\mathbf{1 6 . 2} \pm \mathbf{2 . 1 ^ { * }}$ \\
$\beta$-Carotene $(\mu \mathrm{M})$ & $1.0(0.1-3.4)$ & $1.0(0.2-4.1)$ & $1.2(0.1-3.9)$ & $\mathbf{0 . 8}(\mathbf{0 . 1} \mathbf{- 3 . 6})^{*}$ & $1.2(0.4-4.4)$ & $0.6(0.3-3.9)$ & $1.5(0.3-3.1)$ & $1.2(0.5-1.8)$ \\
\hline
\end{tabular}

Data are shown as mean $\pm \mathrm{SD}$ or median (range) when applicable; ${ }^{*} \mathrm{p}<0.05$ vs controls.

Table 2. Plasma levels of oligoelements and $8-\mathrm{OHdG}$ in diverse human pathologies.

\begin{tabular}{ccccccccc}
\hline & $\begin{array}{c}\text { Controls } \\
(\mathrm{n}=127)\end{array}$ & $\begin{array}{c}\text { Cardiovascular } \\
\text { disease } \\
(\mathrm{n}=136)\end{array}$ & $\begin{array}{c}\text { Psychiatric } \\
\text { disease } \\
(\mathrm{n}=98)\end{array}$ & $\begin{array}{c}\text { Neurodegenerative } \\
\text { disease } \\
(\mathrm{n}=61)\end{array}$ & $\begin{array}{c}\text { Rheumatic } \\
\text { disease } \\
(\mathrm{n}=34)\end{array}$ & $\begin{array}{c}\text { Infectious } \\
\text { disease } \\
(\mathrm{n}=28)\end{array}$ & $\begin{array}{c}\text { Cancer } \\
(\mathrm{n}=24)\end{array}$ & $\begin{array}{c}\text { Endocrinological } \\
\text { disease } \\
(\mathrm{n}=20)\end{array}$ \\
\hline Selenium $(\mu \mathrm{M})$ & $1.36 \pm 0.23$ & $1.39 \pm 0.26$ & $1.42 \pm 0.3$ & $1.31 \pm 0.29$ & $\mathbf{1 . 6 4} \pm \mathbf{0 . 4 1}$ & $1.37 \pm 0.32$ & $1.35 \pm 0.45$ & $1.48 \pm 0.36$ \\
Copper $(\mu \mathrm{M})$ & $16.1 \pm 3.2$ & $15.6 \pm 2.9$ & $15.9 \pm 2.9$ & $\mathbf{1 5 . 0} \pm \mathbf{3 . 3 ^ { * }}$ & $17.6 \pm 2.2$ & $15.7 \pm 3.3$ & $16.8 \pm 3.1$ & $14.7 \pm 5.1$ \\
Zinc $(\mu \mathrm{M})$ & $10.3 \pm 1.2$ & $10.3 \pm 1.8$ & $10.0 \pm 1.6$ & $9.5 \pm 1.9$ & $\mathbf{1 1 . 5} \pm \mathbf{2 . 1 ^ { * }}$ & $10.0 \pm 1.3$ & $10.0 \pm 2.0$ & $10.2 \pm 1.4$ \\
$\begin{array}{c}\text { Urinary } 8-\mathrm{OHdG} \\
(\mu \mathrm{g} / \mathrm{g} \text { creatinine })\end{array}$ & $9.1 \pm 4.2$ & $12.1 \pm 6.6$ & $9.7 \pm 4.0$ & $12.4 \pm 5.4$ & $12.9 \pm 13.6$ & $15.4 \pm 8.3$ & $9.9 \pm 4.4$ & $11.9 \pm 7.0$ \\
\hline
\end{tabular}

Data are shown as mean $\pm \mathrm{SD} ;{ }^{*} \mathrm{p}<0.05$ vs controls.

Table 3. Plasma levels of endogenous antioxidants and activity of GPx in diverse human pathologies.

\begin{tabular}{|c|c|c|c|c|c|c|c|c|}
\hline & $\begin{array}{l}\text { Controls } \\
(\mathrm{n}=127)\end{array}$ & $\begin{array}{c}\text { Cardiovascular } \\
\text { disease } \\
(\mathrm{n}=136)\end{array}$ & $\begin{array}{l}\text { Psychiatric } \\
\text { disease } \\
(\mathrm{n}=98)\end{array}$ & $\begin{array}{c}\text { Neurodegenerative } \\
\text { disease } \\
(\mathrm{n}=61)\end{array}$ & $\begin{array}{l}\text { Rheumatic } \\
\text { disease } \\
(\mathrm{n}=34)\end{array}$ & $\begin{array}{l}\text { Infectious } \\
\text { disease } \\
(\mathrm{n}=28)\end{array}$ & $\begin{array}{l}\text { Cancer } \\
(\mathrm{n}=24)\end{array}$ & $\begin{array}{c}\text { Endocrinological } \\
\text { disease } \\
(\mathrm{n}=20)\end{array}$ \\
\hline $\mathrm{GSH}(\mu \mathrm{M})$ & $936 \pm 193$ & $912 \pm 219$ & $911 \pm 194$ & $917 \pm 172$ & $934 \pm 173$ & $878 \pm 259$ & $862 \pm 172$ & $875 \pm 165$ \\
\hline $\operatorname{GSSG}(\mu \mathrm{M})$ & $53(2-193)$ & $50(0.5-179)$ & $49(2-156)$ & $35(1-127)^{*}$ & $69(5-163)$ & $61(3-114)$ & $33(2-175)$ & $47(20-122)$ \\
\hline $\begin{array}{c}\mathrm{GSH} / \mathrm{GSSG} \\
(\mathrm{mol} / \mathrm{mol})\end{array}$ & $15(2-508)$ & $16(3-612)$ & $16(3-98)^{* * * *}$ & $20(4-162)^{* * *}$ & $10(4-44)^{*}$ & $14(4-60)^{* * * *}$ & $22(3-372)$ & $18(4-36)^{* * * *}$ \\
\hline $\begin{array}{l}\text { GPx activity } \\
(\mathrm{IU} / \mathrm{g} \mathrm{Hb})\end{array}$ & $56.4 \pm 12.7$ & $53.6 \pm 12.4$ & $54.7 \pm 16.6$ & $54.2 \pm 13.3$ & $44.2 \pm 11.1^{\text {** }}$ & $66.3 \pm 24.2$ & $55.7 \pm 17.2$ & $57.0 \pm 11.6$ \\
\hline Total thiols $(\mu \mathrm{M})$ & $365 \pm 53$ & $349 \pm 53^{*}$ & $363 \pm 63$ & $334 \pm 62^{* *}$ & $355 \pm 54$ & $354 \pm 64$ & $358 \pm 61$ & $357 \pm 40$ \\
\hline Urate $(\mu \mathrm{M})$ & $282 \pm 81$ & $304 \pm 82^{*}$ & $273 \pm 76$ & $282 \pm 69$ & $255 \pm 61$ & $308 \pm 88$ & $284 \pm 85$ & $277 \pm 72$ \\
\hline
\end{tabular}

Data are shown as mean $\pm \mathrm{SD}$ or median (range) when applicable; ${ }^{* * *} \mathrm{p}<0.001 ;{ }^{* *} \mathrm{p}<0.01 ;{ }^{*} \mathrm{p}<0.05$ vs controls.

pathologies vs controls (Table 3). Circulating levels of total thiols are significantly decreased in the cardiovascular disease group ( $4 \%, \mathrm{p}<0.05$ vs. controls); by contrast, plasma concentration of urate is significantly increased in this group $(+8 \%, \mathrm{p}<0.05$; Table 2$)$. In addition, plasma concentration of thiols is significantly decreased in the group of patients with neurodegenerative disorders $(-8 \%, \mathrm{p}<0.01$ vs controls).

GPX activity (Table 3): GPx activity is significantly lower in subjects with rheumatic disease $(-22 \%, \mathrm{p}<0.01$ vs control; Table 3).

8-OHdG (Table 2): Urinary levels of $8-\mathrm{OHdG}$ are higher but with no statistical significance in neurodegenerative $(+36 \%, \mathrm{p}=0.18)$, rheumatic $(+4 \%, \mathrm{p}=0.17)$ and infectious $(+69 \%, \mathrm{p}=0.07)$ diseases groups.

Correlations (Table 4): Multiple significant correla- tions are observed between biomarkers of oxidative stress and age. Plasma levels of vitamin $\mathrm{C}(\mathrm{r}=-0.15, \mathrm{p}<$ $0.001)$, thiols $(\mathrm{r}=-0.32, \mathrm{p}<0.001)$, GSSG $(\mathrm{r}=-0.09, \mathrm{p}$ $<0.05)$ and zinc $(\mathrm{r}=-0.20, \mathrm{p}<0.001)$ are significantly correlated with age. At the opposite, concentrations of vitamin $\mathrm{E}(\mathrm{r}=0.27, \mathrm{p}<0.001)$, cholesterol-normalised vitamin $\mathrm{E}(\mathrm{r}=0.26, \mathrm{p}<0.001)$, urate $(\mathrm{r}=0.17, \mathrm{p}<0.001)$ and GSH/GSSG ratio $(r=0.10, p<0.05)$ show positive correlations. Logically, the vitamin $\mathrm{C} /$ vitamin $\mathrm{E}$ ratio is strongly negatively correlated with age $(\mathrm{r}=-0.25, \mathrm{p}<$ $0.001)$. Next, a number of significant correlations between biomarkers of oxidative stress (Table 4) have been identified. Indeed, plasma levels of vitamin $\mathrm{C}$ are positively correlated with those of $\beta$-carotene and selenium but negatively with those of urate, as well as urate and copper; concentrations of vitamin $\mathrm{E}$ is correlated 
Table 4. Correlations between biomarkers of oxidative stress in diverse human pathologies.

\begin{tabular}{|c|c|c|c|c|c|c|c|c|c|c|c|c|}
\hline & vitE & $\beta \mathrm{Car}$ & GSH & GSSG & GSH/GSSG & GPx & Thiols & Urate & $\mathrm{Se}$ & $\mathrm{Cu}$ & $\mathrm{Zn}$ & 8-OHdG \\
\hline Vitamin C & 0.05 & $0.22^{* \text { *** }}$ & 0.02 & -0.03 & -0.06 & 0.02 & -0.03 & $-0.12^{* *}$ & $0.15^{*}$ & 0.01 & $0.19^{* *}$ & 0.10 \\
\hline Vitamin E & & $0.15^{* *}$ & -0.03 & 0.01 & 0.01 & 0.01 & -0.07 & $0.15^{* * * *}$ & $0.37^{* * *}$ & 0.01 & 0.13 & 0.02 \\
\hline$\beta$-Carotene & & & $0.12^{* *}$ & $0.09^{*}$ & 0.07 & 0.13 & $0.13^{* *}$ & 0.02 & -0.05 & 0.10 & $0.13^{*}$ & -0.12 \\
\hline GSH & & & & $0.24^{* * * *}$ & 0.05 & 0.02 & 0.06 & -0.06 & -0.01 & -0.05 & $0.19^{* * *}$ & 0.06 \\
\hline GSSG & & & & & $-0.43^{* * * *}$ & -0.03 & 0.07 & 0.00 & -0.04 & -0.12 & $0.16^{*}$ & -0.05 \\
\hline GSH/GSSG & & & & & & 0.03 & -0.01 & 0.03 & 0.00 & 0.12 & -0.03 & 0.09 \\
\hline GPx & & & & & & & -0.04 & 0.05 & 0.11 & 0.06 & 0.02 & -0.03 \\
\hline Thiols & & & & & & & & -0.07 & -0.10 & -0.05 & $0.18^{* * *}$ & -0.03 \\
\hline Urate & & & & & & & & & -0.06 & $-0.16^{*}$ & -0.06 & -0.01 \\
\hline $\mathrm{Se}$ & & & & & & & & & & $0.14^{*}$ & $0.41^{* * * *}$ & 0.03 \\
\hline $\mathrm{Cu}$ & & & & & & & & & & & $0.18^{* *}$ & 0.12 \\
\hline $\mathrm{Zn}$ & & & & & & & & & & & & -0.06 \\
\hline
\end{tabular}

${ }^{* * *} \mathrm{p}<0.001 ;{ }^{* *} \mathrm{p}<0.01 ;{ }^{*} \mathrm{p}<0.05$

with those of $\beta$-carotene, urate and selenium, as well as the level of $\beta$-carotene with those of GSH, thiols and zinc; GSH is positively correlated with GSSG and zinc as well as GSSG and $\mathrm{Zn}$ with thiol. Concentrations of zinc, selenium and copper are positively correlated. In fine, plasma concentrations of cholesterol, vitamin $\mathrm{E}(\mathrm{r}=0.20, \mathrm{p}<$ $0.001)$ and urate $(\mathrm{r}=0.15, \mathrm{p}<0.001)$ are correlated between them and with age $(\mathrm{r}=0.11, \mathrm{p}<0.01)$.

\section{DISCUSSION AND CONCLUSIONS}

Oxidative stress is a well-known factor in the development of human cardiovascular, neurodegenerative and inflammatory pathologies, in infectious diseases, and in aging [1-5]. Interestingly, in our descriptive study, the major classes of human diseases reveal distinct profiles of oxidative stress biomarkers. Multiple anomalies of these biomarkers have been observed in plasma, whole blood and urine in our patients. Among exogenouslysupplied substances, plasma levels of vitamin E (normalised to cholesterol) are significantly lowered in subjects with psychiatric, infectious and endocrinological troubles, whereas the concentration of $\beta$-carotene is significantly lower in subjects with neurodegenerative diseases. Subnormal levels of vitamin $\mathrm{E}$ and $\beta$-carotene may reflect either insufficient dietary supply, or accelerated consumption as a result of important oxidative stress, or both. Our observations do not allow to conclude, but rather suggest dietary abnormalities as urine levels of 8-OHdG, a biomarker of oxidative DNA damage, are not increased in these conditions (see below). In addition, plasma concentrations of selenium and zinc are significantly higher in patients with rheumatic disease, whereas concentration of copper is significantly lower in subjects with neurodegenerative disorders, suggesting dietary imbalance.
Endogenous antioxidants equally reveal a series of differences vs controls. Erythrocyte GSH/GSSG ratio is significantly lower in subjects with infectious and rheumatic disease but significantly higher in subjects with psychiatric, neurodegenerative and endocrinological disorders. Level of GSSG is subnormal in patients with neurodegenerative disorders. GPx activity is significantly lower in the rheumatic disease group. Decreased GSH/ GSSG ratios in erythrocytes may be indicative of elevated oxidative stress and poor regeneration of GSH; by contrast, an elevated ratio (and decreased levels of GSSG) is consistent with an upregulation of GSH recycling, potentially in response to elevated oxidative stress.

Circulating levels of total thiols are significantly lowered in subjects with cardiovascular and neurodegenerative disorders, suggesting a low total reductive capacity of plasma. A poor recycling of homocysteine via the cystathionine beta synthase pathway (CBS) leads to shortage of cysteine then to a decreased glutathion synthesis. This defective pathway is usually a characteristic of cardiovascular pathologies [19]. Indeed, total SH groups critically contribute to the total antioxidative capacity of plasma measured using in vitro assays $[20,21]$. In fine, plasma concentrations of urate are significantly increased in subjects with cardiovascular disease. Indeed, this group of patients is characterised by diminished plasma concentrations of total thiols, associated with an important concentration of urate. This may be also linked to the older age observed in this group: plasma levels of thiols and urate correlate respectively negatively and positively with age. The progressive elevation of circulating concentrations of uric acid with age is well documented $[22,23]$. As urate and total thiols represent two major parameters of total radical-trapping capacity of human plasma $[20,21,24]$, their differential modulations in pres- 
ence of cardiovascular disease is consistent with normal values of the biomarker of oxidative DNA damage (8$\mathrm{OHdG}$ ), suggesting a compensatory effect.

In clear contrast, patients with neurodegenerative disorders (Alzheimer's disease, Parkinson's disease or multiple sclerosis) show decreased levels of $\beta$-carotene, thiols and copper but a high GSH/GSSG ratio. Decreased plasma levels of carotenes have been previously reported in Alzheimer's disease [25-28] and multiple sclerosis [29]; they reflect an inproper dietary supply [30]. Low concentrations of total thiols, reported also in neurodegerative disorders [28,31], are probably the result of an accelerated turn-over linked to an elevated oxidative stress. By contrast, an alteration of circulating levels of transition metals in Alzheimer's disease, Parkinson's disease and multiple sclerosis remains controversial [3234]. Finally, improved redox status of glutathione in subjects displaying neurodegenerative diseases may be the result of an increased glutathione synthase activity, a key enzyme involved in the synthesis of GSH, as already mentioned [35].

Patients with psychiatric disease (depressive syndrome or anxiety) reveal lower values of cholesterol-normalised vitamin E and increased GSH/GSSG ratio. Intriguingly, similar alterations in oxidative stress biomarkers have been observed in subjects with endocrinological disease (thyroid dysfunction). Low concentrations of vitamin $\mathrm{E}$ have been reported in major depression syndroms $[36,37]$ potentially reflecting an inadequate nutritional behaviour. Improved redox status of glutathione may result in turn from elevated activity of glutathione reductase [38].

A cluster of abnormalities are detected in subjects with rheumatic disease; these includes diminished GSH/GSSG ratio and GPx activity and high concentrations of selenium and zinc. Deficiency in cellular glutathione-based antioxidative systems is well established in rheumatic arthritis: it typically involves defective recycling and impaired redox status of glutathione [39-41]. By contrast, loss of GPx activity is rather less documented [39,42]. Up regulation of GPx activity has also been reported in patients with arthritis [40,41], in response to chronic oxidative stress. Increased plasma levels of selenium and zinc are rather unexpected: rheumatic diseases are frequently characterised by deficiencies in these trace elements $[39,43,44]$. High levels may be the result of a nutritional supplementation, common in Western societies: $\mathrm{Zn}$ deficiencies have been described in $15 \%$ of the caucasian population [45] and supplementation is often suggested; on the contrary no deficiency in Selenium has ever been described in caucasian population and this abnormally high level is undoubtedly the result of supplementation.

Patients with viral infection (HIV or hepatitis C) are characterised by decreased levels of vitamin E (normal- ised to cholesterol) and impaired redox status of glutathione. Vitamin E is typically low in subjects infected with HIV [46], most probably as a result of suboptimal nutritional intake [47]. Such insufficient exogenous supplies of antioxidants may lead to an accelerated consumption of endogenous antioxidants as shown by the decrease in the GSH/GSSG ratio [48,49]. By contrast, hepatitis $\mathrm{C}$, which is characterised by impaired hepatic function may be associated with a poor metabolism of vitamin E [50,51]. Defective activities of hepatic enzymes involved in glutathione metabolism can be involved in the decreased GSH/GSSG ratio in blood cells [52,53].

Interestingly, patients with cancer did not show any abnormality in circulating biomarkers of oxidative stress, despite an older age. This observation is consistent with the broadening consensus regarding a highly specific elevation of oxidative stress in vulnerable cells in individual types of cancer, which results in targeted damage to cellular DNA $[54,55]$; this concept appears more attractive than a non-specific rise in systemic oxidative stress, which may only be relevant at terminal stages of the disease.

Intriguingly, the only biomarker of oxidative damage evaluated in this study, urinary $8-\mathrm{OHdG}$, does not show significant differences between the groups and only tends to be higher in subjects with neurodegenerative, rheumatic and infectious disease. This means that damages to nuclear biomolecules cannot be observed despite significant decrements in levels of individual protective antioxidants.

In conclusion, our identification of distinct patterns of oxidative stress biomarkers in specific pathologies strongly suggests the involvement of multiple specific forms of oxidative insults related to each pathological condition. In practical terms, such a highly diverse picture implies that a specific array of biomarkers should be measured in order to fully cover the variety of patterns present in different pathologies. This complex feature is further highlighted by multiple correlations observed between the different biomarkers. Furthermore, these data imply that an integrated score should be developed to enable quantitative comparison between the different patterns; Population screening, in order to quantitatively assess the oxidative stress in an integrated manner, should be of special relevance. This would allow to identify subjects who present increased oxidative stress, as a criterion for inclusion in clinical studies designed to determine specific antioxidant therapies. This explains why current antioxidant treatments, cocktails of numerous vitamins and oligoelements, given haphazardly, irrespectively of clinically quantified deficiencies, are poorly efficient and potentially detrimental $[56,57]$. 


\section{ACKNOWLEDGEMENTS}

MB gratefully acknowledges excellent technical assistance by Joel Pincemail (CHU Liège, Belgium). MJC and AK gratefully acknowledge the award of a Contrat d'Interface from Assistance PubliqueHôpitaux de Paris/INSERM (France).

\section{REFERENCES}

[1] Halliwell, B. and Gutteridge, J.M. (1989) Free radicals in biology and medicine. Clarendon Press, Oxford.

[2] Van Lenten, B.J., Navab, M., Shih, D., Fogelman, A.M. and Lusis, A.J. (2001) The role of high-density lipoproteins in oxidation and inflammation. Trends in Cardiovascular Medicine, 11, 155-161. doi:10.1016/S1050-1738(01)00095-0

[3] Stocker, R. and Keaney Jr., J.F. (2004) Role of oxidative modifications in atherosclerosis. Trends in Cardiovascular Medicine, 84, 1381-1478. doi:10.1152/physrev.00047.2003

[4] Barnham, K.J., Masters, C.L. and Bush, A.I. (2004) Neurodegenerative diseases and oxidative stress. Nature Reviews Drug Discovery, 3, 205-214. doi:10.1038/nrd1330

[5] Floyd, R.A. and Hensley, K. (2002) Oxidative stress in brain aging. Implications for therapeutics of neurodegenerative diseases. Neurobiology of Aging, 23, 795-807. doi:10.1016/S0197-4580(02)00019-2

[6] Halliwell, B. (1999) Antioxidant defence mechanisms: From the beginning to the end (of the beginning). Free Radical Research, 31, 261-272. doi:10.1080/10715769900300841

[7] Therond, P., Bonnefont-Rousselot, D., Davit-Spraul, A., Conti, M. and Legrand, A. (2000) Biomarkers of oxidative stress: An analytical approach. Current Opinion in Clinical Nutrition \& Metabolic Care, 3, 373-384. doi:10.1097/00075197-200009000-00009

[8] Dalle-Donne, I., Rossi, R., Colombo, R., Giustarini, D. and Milzani, A. (2006) Biomarkers of oxidative damage in human disease. Clinical Chemistry, 52, 601-623. doi:10.1373/clinchem.2005.061408

[9] Kadiiska, M.B., Gladen, B.C., Baird, D.D., Germolec, D., Graham, L.B., Parker, C.E., Nyska, A., Wachsman, J.T., Ames, B.N., Basu, S., Brot, N., Fitzgerald, G.A., Floyd, R.A., George, M., Heinecke, J.W., Hatch, G.E., Hensley, K., Lawson, J.A., Marnett, L.J., Morrow, J.D., Murray, D.M., Plastaras, J., Roberts II, L.J., Rokach, J., Shigenaga, M.K., Sohal, R.S., Sun, J., Tice, R.R., Van Thiel, D.H., Wellner, D., Walter, P.B., Tomer, K.B., Mason, R.P. and Barrett, J.C. (2005) Biomarkers of oxidative stress study II: Are oxidation products of lipids, proteins, and DNA markers of $\mathrm{CCl} 4$ poisoning? Free Radical Biology \& Medicine, 38, 698-710. doi:10.1016/j.freeradbiomed.2004.09.017

[10] Kadiiska, M.B., Gladen, B.C., Baird, D.D., Graham, L.B., Parker, C.E., Ames, B.N., Basu, S., Fitzgerald, G.A., Lawson, J.A., Marnett, L.J., Morrow, J.D., Murray, D.M., Plastaras, J., Roberts II, L.J., Rokach, J., Shigenaga, M.K., Sun, J., Walter, P.B., Tomer, K.B., Barrett, J.C. and Mason, R.P. (2005) Biomarkers of oxidative stress study III.
Effects of the nonsteroidal anti-inflammatory agents indomethacin and meclofenamic acid on measurements of oxidative products of lipids in $\mathrm{CCl} 4$ poisoning. Free Radical Biology and Medicine, 38, 711-718. doi:10.1016/j.freeradbiomed.2004.10.024

[11] Witztum, J.L. and Steinberg, D. (2001) The oxidative modification hypothesis of atherosclerosis: Does it hold for humans? Trends in Cardiovascular Medicine, 11, 93102. doi:10.1016/S1050-1738(01)00111-6

[12] Heinecke, J.W. (2001) Is the emperor wearing clothes? Clinical trials of vitamin $\mathrm{E}$ and the LDL oxidation hypothesis. Arteriosclerosis, Thrombosis, and Vascular Biology, 21, 1261-1264. doi:10.1161/hq0801.095084

[13] Hercberg, S., Galan, P., Preziosi, P., Bertrais, S., Mennen, L., Malvy, D., Roussel, A.M., Favier, A. and Briancon, S. (2004) The SU.VI.MAX Study: A randomized, placebocontrolled trial of the health effects of antioxidant vitamins and minerals. Archives of Internal Medicine, 164, 2335-2342. doi:10.1001/archinte.164.21.2335

[14] Omaye, S.T., Turnbull, J.D. and Sauberlich, H.E. (1979) Selected methods for the determination of ascorbic acid in animal cells, tissues, and fluids. Methods in Enzymology, 62, 3-11. doi:10.1016/0076-6879(79)62181-X

[15] Zhao, B., Tham, S.Y., Lu, J., Lai, M.H., Lee, L.K. and Moochhala, S.M. (2004) Simultaneous determination of vitamins $\mathrm{C}, \mathrm{E}$ and beta-carotene in human plasma by high-performance liquid chromatography with photodiode-array detection. Journal of Pharmaceutical Sciences, 7, 200-204.

[16] Sturup, S., Hayes, R.B. and Peters, U. (2005) Development and application of a simple routine method for the determination of selenium in serum by octopole reaction system ICPMS. Analytical and Bioanalytical Chemistry, 381, 686-694. doi:10.1007/s00216-004-2946-x

[17] Tietze, F. (1969) Enzymic method for quantitative determination of nanogram amounts of total and oxidized glutathione: Applications to mammalian blood and other tissues. Analytical Biochemistry, 27, 502-522. doi:10.1016/0003-2697(69)90064-5

[18] Motchnik, P.A., Frei, B. and Ames, B.N. (1994) Measurement of antioxidants in human blood plasma. Methods in Enzymology, 234, 269-279. doi:10.1016/0076-6879(94)34094-3

[19] Hoffman, M. (2011) Hypothesis: Hyperhomocysteinemia is an indicator of oxidant stress. Medical Hypotheses, 77, 1088-1093. doi:10.1016/j.mehy.2011.09.009

[20] Wayner, D.D., Burton, G.W., Ingold, K.U., Barclay, L.R. and Locke, S.J. (1987) The relative contributions of vitamin E, urate, ascorbate and proteins to the total peroxyl radical-trapping antioxidant activity of human blood plasma. Biochimica et Biophysica Acta, 924, 408-419. doi:10.1016/0304-4165(87)90155-3

[21] Balcerczyk, A., Grzelak, A., Janaszewska, A., Jakubowski, W., Koziol, S., Marszalek, M., Rychlik, B., Soszynski, M., Bilinski, T. and Bartosz, G. (2003) Thiols as major determinants of the total antioxidant capacity. Biofactors, 17, 75-82. doi:10.1002/biof.5520170108

[22] Kuzuya, M., Ando, F., Iguchi, A. and Shimokata, H. (2002) Effect of aging on serum uric acid levels: Longi- 
tudinal changes in a large Japanese population group. Journals of Gerontology Series A: Biological Sciences and Medical Sciences, 57, M660-M664. doi:10.1093/gerona/57.10.M660

[23] Hak, A.E. and Choi, H.K. (2008) Menopause, postmenopausal hormone use and serum uric acid levels in US women-The third national health and nutrition examination survey. Arthritis Research \& Therapy, 10, R116. doi:10.1186/ar2519

[24] Sautin, Y.Y. and Johnson, R.J. (2008) Uric acid: The oxidant-antioxidant paradox. Nucleosides, Nucleotides and Nucleic Acids, 27, 608-619. doi:10.1080/15257770802138558

[25] Zaman, Z., Roche, S., Fielden, P., Frost, P.G., Niriella, D.C. and Cayley, A.C. (1992) Plasma concentrations of vitamins A and $\mathrm{E}$ and carotenoids in Alzheimer's disease. Age Ageing, 21, 91-94. doi:10.1093/ageing/21.2.91

[26] Schippling, S., Kontush, A., Arlt, S., Buhmann, C., Sturenburg, H.J., Mann, U., Muller-Thomsen, T. and Beisiegel, U. (2000) Increased lipoprotein oxidation in Alzheimer's disease. Free Radical Biology \& Medicine, 28, 351-360. doi:10.1016/S0891-5849(99)00247-6

[27] Mecocci, P., Polidori, M.C., Cherubini, A., Ingegni, T., Mattioli, P., Catani, M., Rinaldi, P., Cecchetti, R., Stahl, W., Senin, U. and Beal, M.F. (2002) Lymphocyte oxidative DNA damage and plasma antioxidants in Alzheimer disease. Archives of Neurology, 59, 794-798. doi:10.1001/archneur.59.5.794

[28] Polidori, M.C. and Mecocci, P. (2002) Plasma susceptibility to free radical-induced antioxidant consumption and lipid peroxidation is increased in very old subjects with Alzheimer disease. Journal of Alzheimer's Disease, 4, 517-522.

[29] Besler, H.T., Comoglu, S. and Okcu, Z. (2002) Serum levels of antioxidant vitamins and lipid peroxidation in multiple sclerosis. Nutritional Neuroscience, 5, 215-220. doi:10.1080/10284150290029205

[30] Jimenez-Jimenez, F.J., Molina, J.A., de Bustos, F., OrtiPareja, M., Benito-Leon, J., Tallon-Barranco, A., Gasalla, T., Porta, J. and Arenas, J. (1999) Serum levels of betacarotene, alpha-carotene and vitamin $\mathrm{A}$ in patients with Alzheimer's disease. European Journal of Neurology, 6, 495-497. doi:10.1046/j.1468-1331.1999.640495.x

[31] Buhmann, C., Arlt, S., Kontush, A., Moller-Bertram, T., Sperber, S., Oechsner, M., Stuerenburg, H.J. and Beisiegel, U. (2004) Plasma and CSF markers of oxidative stress are increased in Parkinson's disease and influenced by antiparkinsonian medication. Neurobiology of Disease, 15, 160-170. doi:10.1016/i.nbd.2003.10.003

[32] Palm, R. and Hallmans, G. (1982) Zinc and copper in multiple sclerosis. Journal of Neurology, Neurosurgery \& Psychiatry, 45, 691-698. doi:10.1136/jnnp.45.8.691

[33] Jimenez-Jimenez, F.J., Fernandez-Calle, P., MartinezVanaclocha, M., Herrero, E., Molina, J.A., Vazquez, A. and Codoceo, R. (1992) Serum levels of zinc and copper in patients with Parkinson's disease. Journal of the Neurological Sciences, 112, 30-33. doi:10.1016/0022-510X(92)90127-7

[34] Bush, A.I. and Strozyk, D. (2004) Serum copper: A bio- marker for Alzheimer disease? Archives of Neurology, 61, 631-632. doi:10.1001/archneur.61.5.631

[35] Tchantchou, F., Graves, M., Ortiz, D., Rogers, E. and Shea, T.B. (2004) Dietary supplementation with apple juice concentrate alleviates the compensatory increase in glutathione synthase transcription and activity that accompanies dietary- and genetically-induced oxidative stress. Journal of Nutrition Health and Aging, 8, 492-496.

[36] Maes, M., De Vos, N., Pioli, R., Demedts, P., Wauters, A., Neels, H. and Christophe, A. (2000) Lower serum vitamin $\mathrm{E}$ concentrations in major depression. Another marker of lowered antioxidant defenses in that illness. Journal of Affective Disorders, 58, 241-246. doi:10.1016/S0165-0327(99)00121-4

[37] Tiemeier, H., Hofman, A., Kiliaan, A.J., Meijer, J. and Breteler, M.M. (2002) Vitamin E and depressive symptoms are not related. The Rotterdam Study. Journal of Affective Disorders, 72, 79-83. doi:10.1016/S0165-0327(01)00427-X

[38] Bilici, M., Efe, H., Koroglu, M.A., Uydu, H.A., Bekaroglu, M. and Deger, O. (2001) Antioxidative enzyme activities and lipid peroxidation in major depression: Alterations by antidepressant treatments. Journal of Affective Disorders, 64, 43-51. doi:10.1016/S0165-0327(00)00199-3

[39] Tarp, U., Stengaard-Pedersen, K., Hansen, J.C. and Thorling, E.B. (1992) Glutathione redox cycle enzymes and selenium in severe rheumatoid arthritis: Lack of antioxidative response to selenium supplementation in polymorphonuclear leucocytes. Annals of the Rheumatic Diseases, 51, 1044-1049. doi:10.1136/ard.51.9.1044

[40] Hassan, M.Q., Hadi, R.A., Al-Rawi, Z.S., Padron, V.A. and Stohs, S.J. (2001) The glutathione defense system in the pathogenesis of rheumatoid arthritis. Journal of Applied Toxicology, 21, 169-173. doi:10.1002/jat.736

[41] Surapaneni, K.M. and Venkataramana, G. (2007) Status of lipid peroxidation, glutathione, ascorbic acid, vitamin $\mathrm{E}$ and antioxidant enzymes in patients with osteoarthritis. Indian Journal of Medical Sciences, 61, 9-14. doi:10.4103/0019-5359.29592

[42] Mulherin, D.M., Thurnham, D.I. and Situnayake, R.D. (1996) Glutathione reductase activity, riboflavin status, and disease activity in rheumatoid arthritis. Annals of the Rheumatic Diseases, 55, 837-840. doi:10.1136/ard.55.11.837

[43] Honkanen, V., Konttinen, Y.T., Sorsa, T., Hukkanen, M., Kemppinen, P., Santavirta, S., Saari, H. and Westermarck, T. (1991) Serum zinc, copper and selenium in rheumatoid arthritis. Journal of Trace Elements and Electrolytes in Health and Disease, 5, 261-263.

[44] Yazar, M., Sarban, S., Kocyigit, A. and Isikan, U.E. (2005) Synovial fluid and plasma selenium, copper, zinc, and iron concentrations in patients with rheumatoid arthritis and osteoarthritis. Biological Trace Element Research, 106, 123-132. doi:10.1385/BTER:106:2:123

[45] Centers for Disease Control and Prevention (CDC), National Center for Health Statistics (NCHS) (2002) National Health and Nutrition Examination Survey Questionnaire. Hyattsville. 
http://www.cdc.gov/nchs/about/major/nhanes/nhanes01-0 2.htm

[46] Jordao Jr., A.A., Silveira, S., Figueiredo, J.F. and Vannucchi, H. (1998) Urinary excretion and plasma vitamin E levels in patients with AIDS. Nutrition, 14, 423-426. doi:10.1016/S0899-9007(98)00012-4

[47] Baum, M., Cassetti, L., Bonvehi, P., Shor-Posner, G., Lu, Y. and Sauberlich, H. (1994) Inadequate dietary intake and altered nutrition status in early HIV-1 infection. $\mathrm{Nu}$ trition, 10, 16-20.

[48] Delmas-Beauvieux, M.C., Peuchant, E., Couchouron, A., Constans, J., Sergeant, C., Simonoff, M., Pellegrin, J.L., Leng, B., Conri, C. and Clerc, M. (1996) The enzymatic antioxidant system in blood and glutathione status in human immunodeficiency virus (HIV)-infected patients: Effects of supplementation with selenium or beta-carotene. American Journal of Clinical Nutrition, 64, 101107.

[49] Jahoor, F., Jackson, A., Gazzard, B., Philips, G., Sharpstone, D., Frazer, M.E. and Heird, W. (1999) Erythrocyte glutathione deficiency in symptom-free HIV infection is associated with decreased synthesis rate. American Journal of Physiology, 276, E205-E211.

[50] Von Herbay, A., Stahl, W., Niederau, C., von Laar, J., Strohmeyer, G. and Sies, H. (1996) Diminished plasma levels of vitamin $\mathrm{E}$ in patients with severe viral hepatitis. Free Radical Research, 25, 461-466. doi:10.3109/10715769609149068

[51] Jain, S.K., Pemberton, P.W., Smith, A., McMahon, R.F., Burrows, P.C., Aboutwerat, A. and Warnes, T.W. (2002)
Oxidative stress in chronic hepatitis C: Not just a feature of late stage disease. Journal of Hepatology, 36, 805-811. doi:10.1016/S0168-8278(02)00060-0

[52] Swietek, K. and Juszczyk, J. (1997) Reduced glutathione concentration in erythrocytes of patients with acute and chronic viral hepatitis. Journal of Viral Hepatitis, 4, 139141.

[53] Loguercio, C., Blanco, F.D., De Girolamo, V., Disalvo, D., Nardi, G., Parente, A. and Blanco, C.D. (1999) Ethanol consumption, amino acid and glutathione blood levels in patients with and without chronic liver disease. Alcoholism: Clinical and Experimental Research, 23, 17801784. doi:10.1111/j.1530-0277.1999.tb04073.x

[54] Toyokuni, S. (2008) Molecular mechanisms of oxidative stress-induced carcinogenesis: From epidemiology to oxygenomics. International Union of Biochemistry and Molecular Biology, 60, 441-447. doi:10.1002/iub.61

[55] Gupte, A. and Mumper, R.J. (2009) Elevated copper and oxidative stress in cancer cells as a target for cancer treatment. Cancer Treatment Reviews, 35, 32-46. doi:10.1016/i.ctrv.2008.07.004

[56] Ménézo, Y., Entezami, F., Lichtblau, I., Belloc, S., Cohen, M. and Dale, B. (2012) Oxidative stress and fertility: Incorrect assumptions and ineffective solutions? Zygote, 12, 1-11. doi:10.1017/S0967199412000263

[57] Bjelakovic, G., Nikolova, D., Gluud, L.L., Simonetti, R.G. and Gluud, C. (2008) Antioxidant supplements for prevention of mortality in healthy participants and patients with various diseases. Cochrane Database of Systematic Reviews, 16, Article ID: CD007176. 